\title{
PERENCANAAN GLOWING IN THE DARK PADA LORONG KAMPUS UNIVERSITAS POTENSI UTAMA
}

\author{
Suprianingsih \\ Program Studi Desain Interior, Fakultas Seni dan Desain, \\ Universitas Potensi Utama \\ Suprianingsih97@gmail.com
}

\begin{abstract}
ABSTRAK
Perencanaan glowing in the dark pada lorong kampus universitas potensi utama adalah sebuah desain interior yang memanfaatkan bagian sudut dari lorong yang ada pada lingkungan kampus sebagai media untuk mengaplikasi lukisan yang bertema galaksi sebagai wujud dari desain interior yang menggunakan cat khusus yaitu cat glowing in the dark. Cat ini dapat meyerap cahanya yang dihasilkan dari lampu yang ada disekitarnya dan akan dipancarkan kembali apabila cahanya di padamkan Hal ini dikarenakan system kerja cat glowing in the dark yang seperti panel surya yang menyerap cahaya disekitarnya dan mengalirkan kembali disaat cahanya disekitarnya padam. Glowing in the dark dirancang untuk menunjukan exsistensi dan menunjukan pengembangan dari desain interior yang sesuai dengan perkembangan jaman saat ini.
\end{abstract}

Kata kunci : cat, Lorong, glowing in the dark

\begin{abstract}
The design of Glowing In The Dark on Campus Hallway is an interior design that utilizes the angular part of the Hallway in the campus environment as a medium for the application of galaxy-themed paintings as a manifestation of interior design that uses special paints that are glowing in the dark paint. This paint can absorb the heat produced from the lights around it and will be re-emitted when the light is matched. This is because the working system of paint glowing in the dark is like a solar panel that absorbs the surrounding light and flows back when the light is extinguished. Glowing in the dark is designed to show existance and shows the development of interior design that is in line with the current developments.
\end{abstract}

Keywords: paint, hallway, glowing in the dark

\section{PENDAHULUAN}

Pesatnya perkembangan jaman baik dari perkembangan teknologi, cara berpikir, kebutuhan hidup, perkembangan desain dan perkembangan sosial, seni dan budaya. Perkembangan yang paling menonjol ialah perkembangan teknologi dan desain. Perkembangan terknologi dapat dilihat semakin canggihnya alat elektronik untuk kebutuhan sehari-hari, sedangkan dalam perkembangan dunia desain terlihat dari semakin 
meningkatnya ruang publik yang didesain sedemikian rupa sehingga menarik minat masyarakat untuk datang kelokasi tersebut.

Mendesain sebuah ruang publik terdapat beberapa aspek desain yaitu aspek arsitektur interior, aspek estetika pungsional dan aspek karakterisasi identitas harus diperhatikan seperti yang diperlukan untuk mendesain sebuah ruang publik agar sesuai dengan sasaran dan tujuan yang diinginkan dalam perancangan tersebut.

Perencanaan glowing in the dark pemilihan warna yang sesuai dengan tema sangatlah diperhatikan, warna ialah sebuah spektrum yang terdapat pada cahaya sempurna ( berwarna putih). Penentuan identitas esbuah warna ditentukan melalui panjang gelombang cahaya tersebut yang mampu ditangkap oleh mata manusia.

Hubung warna pada desai interior ialah efek yang ditimbulkan dari warna yang dilihat atau warna yang digunakan oleh seorang desain. Karna warna dapat mempengaruhi pisikologi dari orang tersebut. Ketepatan penggunaan warna pada desain interior sangatlah mempengaruhi hasil desain. Karena penggunaan warna yang tepat akan membawa kebahagian dan kedamaian bagi penikmat.

Glowing in the dark diartikan sebgai cahaya yang menyala atau berpendarnya cahaya tanpa adanya energi listrik secara langsung. Glowing in the dark ialah sebuah cat yang dapat menyerap energi dari cahaya yang ada disekitarnya dan akan dipancarkan kembali apabila kondisi yang disekitarnya gelap. Hal ini terjadi karna system kerja dari cat glowing in the dark menyerap energi cahaya yang ada disekitarnya.

\section{STUDI LITERATUR}

\section{II.1. Perancangan Glowing in the dark Pada Lorong Kampus Universitas Potensi utama.}

Perancangan glowing in the dark pada Lorong kampus universitas potensi utama yang akan diimplementasikan pada Lorong lantai dua Gedung B universitas potensi utama. Tema yang diangkat pada perancangan glowing in the dark Lorong kampus universitas potensi utaman ialah galaksi. Tema galaksi dipilih karna dianggap tema yang sesuai dengan kemajuan teknologi dan kemajuan jaman.

II.2. Pengaruh perancangan glowing in the dark Lorong kampus universitas potensi utaman.

Pengaruh yang akan ditimbulkan dari perancangan glowing in the dark Lorong kampus universitas potensi untama ialah memberikan warna seni desain dalam lingkungan universitas, memberikan hal bari bagi mahasiswa universitas potensi utama serta menunjukan exsistensi bidang ilmu desai interior.

II.3. Strategi perancangan glowing in the dark pada Lorong kampus universitas potensi utama.

Strategi perancangan glowing in the dark pada Lorong kampus universitas potensi utama dimulai dari penentuan tema, penetuan lokasi pengaplikasian, penentuan jenis cat glowing in the dark yang digunakan dan persiapan bahan dan alat pengaplikasian.

\section{PEMBAHASAN}

Universitas potensi utama ialah perguruan tinggi yang berdiri dibawah naungan Yayasan Potensi Utama Medan. universitas yang berawal dari sebuah kursus computer dan Bahasa inggris pada tahun 1994 dengan nama "Pendidikan Luar Sekolah Masyarakat" yang 
pada tahun 2003 mendapatkan izin Direktorat Jendral Pendidikan Tinggi (DIKTI), Pendidikan Luar Sekolah Masyarakat berubah menjadi Sekolah Tinggi Manajemen Informatika (STMIK Potensi Utama) dan Komputer. Dan pada tahun 2014 STMIK Potensi Utama berubah bentuk menjadi Universitas Potensi Utama berdasarkan izin kementrian Pendidikan dan kebudayaan dengan surat keputusan SK nomo: 424/E/O/2014 dengam motto" Kami Hadir Untuk Mencerdasakan Kehidupan Bangsa" dengan perubahan statun Universitas Potensi Utama dipercaya membuka 5 fakultas dengan 12 progras studi yakni:

Fakultas Teknik Dan Ilmu Komputer

> Program studi Teknik Informatika (S1)

$>$ Program Studi Sistem Informasi (S1)

$>$ Program studi Teknik industry (S1)

$>$ Manajeman informatika (D3)

Fakultas Seni Dan Desain

$>$ Program Studi Desain Interior (S1)

$>$ Program Studi Desai Komunikasi Visual (S1)

$>$ Program Studi Televisi Dan Filem (S1)

Fakultas Pisikologi

$>$ Program Studi Pisikologi (S1)

Fakultas Ilmu Politik Dan Kependidikan

$>$ Program Studi Hubungan Internasional (S1)

$>$ Pendidikan Bahasa Inggris (S1)

Fakultas Bisnis Syariah

$>$ Program Studiekonomi Syariah (S1)

$>$ Program Studi Perbankan Syariah (S1)

Glowing in the dark (bersinar dalam gelap) ialah cahaya yang bersinar saat gelap hal ini akan terjadi dikarnakan system kerja cat glowing in the dark yang seperti panel surya, yang meyerap cahaya disekitarnya begitu juga cat Glowing in the dark meyerap cahaya disekitarnya yang dihasilkan dari lampu yang meyana dan cahaya yang diserap akan dipancarkan kembali pada saat keadaan gelap atau lampu dimatikan.

Media pengaplikasian yang akan digunakan ialah tembok yang ada pada Lorong kampus universitas potensi utama lokasi ini dipilih karna dinilai sesuai dengan konsep yang akan dibuat serta posisi dan ukuran lorong yang sangat pas untuk pembuatan Glowing in the dark.

Adapun tujuan dari Perencanaan glowing in the dark pada lorong kampus universitas potensi utama ialah sebgai berikut:

$>$ Memberikan sentuhan seni desain dalam lingkungan kampus universitas potensi utama.

$>$ Memberikan hal baru dalam lingkungan kampus universitas potensi utama.

$>$ Memperkenalkan desain interior pada mahasiswa yang bukan dari bidang ilmu desain.

\section{III.1. Ruang Lingkup Perancangan}

Perancangan glowing in the dark pada Lorong kampus universitas potensi utama agar perancangan ini sesuai dengan tujuan yang ingin dicapai maka perlunya batasi dalam ruang lingkup perancangan pencarian data yang hanya dilingkungan universitas. Baik penentuan lokasi implementasi, penentuan tema dan penggunaan alat dan bahan semuanya disesuaikan dengan lingkup universitas potensi utaman. 
Target utama dalam perancangan ini adalah para mahasiswa dan sivitas yang ada dalam lingkungan universitas potensi utama sebagai berikut:

a. Demografis

Usia : :19-50 tahun

Terdiri dari : Dewasa dan orang tua.

Jenis kelamin : perempuan dan laki-laki

b. Geografis

Lokasi sasaran yang di tuju dalam perancangan ini adalah Gedung B universitas potensi utama

c. Psikografi

Secara psikologi perancangan glowing in the dark pada Lorong kampus universitas potensi utama untuk mempengaruhi prilaku dan pola pikir para mahasiswa dan sifitas akademik universitas potensi utama terhadap desain interior dan senin melalui karya seni.

\section{III.2. Unsur-Unsur Perancangan Desain Interior}

Untuk menciptakan sebuah rancangan desain interior beberapa aspek yang harus ditelaah dari manfaat desain yang akan dihasilkan sebagai berikut;

a. $\quad$ Sudut Pandang (View)

Dalam dunia desain interior sudut pandang ialah suatu penentuan posisi sebuah sudut atau ruang untuk mendapatkan nilai atau arah pandangan terbaik dari sipengunan ruangan tersebut.

cara pandang seseorang terhadap suatu hal tidaklah sama, hal ini dengeparuhi oleh selerah dari setiap orang yang berbeda-beda yang akan menghasilkan pendapat atau selerah yang berbeda pula. Meskipun pandangan setiap orang berbeda-beda namu tidak jarang beberapa orang akah memiliki pandagan atau pendapat yang sama terhadap suatu hal yang dilihat dan dirasakan.

b. Ruangan

Ruangan ialah sebuah area atau lokasi yang diperuntukan untuk suatu hal tertentu, pada desain interior sebuah ruang memiliki tiga dimensi yaitu memiliki Panjang, tinggi dan lebar.

Pada dasarnya ukuran ruangan memiliki dampak yang sangat besar terhadap sipengguna ruangan baik dampak positif maupun dampak negatip. Contohnya sebuah ruangan yang tidak terlalu luas dapat memberikan kesan ramian dan sibuk dikarnakan ruangan yang tidak terlalu besar namun dapat juga sebaliknya ruangan yang tidak terlalu besar dapat memberikan efek nyaman dikarnakan suasana dan aktifitas yang tidak terlalu padat yang adan memberikan efek nyaman bagi sang pengguna. Sebuah desain interior bukanlah soal seberapa besar ruangan namun lebih bagaimana cara seorang desainner interior mengembalikan fungsi ruangan yang sesungguhnya.

c. Garis

Garis merupak elemn dasar dalam desain interior yang mencakup gerakan terus menerus dari satu titik yang sama sepanjang permukaan, yang membangkitkan respon, emosi, dan penyampaian perasaan. Beberapa penapsiran bentuk garis:

1. Garis vertikal mewakili perasaan bermartabat dan formal yang mengarahkan mata bergerak keatas.

2. Garis horizontal mewakili kesetabilan dan ketenangan, yang merngarhkan mata untuk bergerak dari sisi satu kesisi yang lainnya.

3. Garis melengkung mewakili kelembutan dan rasa santai, yang membuat seseorang merasa nyaman bila melihatnya. 
4. Garis diagonal mewakili ketegangan dan darama dalam sebuah ruang yang akan memberikan sensa menegangkan.

d. Bantuk

Bentuk ialah suatu perwujutan dari sebuah banda atau gambar yang dapat dilihat dan dirasakan (disentuh) oleh sang pengguna. Suatu bentuk dari sebuah banda biasanya dapat diukur mulai dari tinggi, lebar dan keseluruhan dari bantuk benda tersebut. Ada dua jenis bentuk dalam desain interior yaitu;

1. Bentuk buatan manusia ialah segala benda yang wujudnya tercipta atau diciptakan oleh manusia.

2. Bentuk alami ialah segala bentuk benda atau tektur benda yang tercipta dari alam tanpa ada sentuhan manusia didalamnya.

e. Warna

Warna ialah spektrum cahaya yang dipantulkan oleh suatu benda atau objek yang dapat memberikan efek positif dan negative, dalam warna terdapat dua golongan warna yaitu;

1. Warna netral ialah warna-warna yang memiliki sifat nyaman, menenangkan, meyenangkan dan warna yang dapat dikombinasikan dengan warna-warna cerah.

2. Warna cerah ialah warna-warna yang memiliki sifat cerah dan berani yang akan membuat sebuah benda atau ruangan memiliki kesan caeria dan terang.

Penggunaan warna yang tepat pada setiap ruangan atau benda interior akan meningkatkan produktifitas, mood pengguna ruangan dan keyamanan saat berada didalam ruangan tersebut. Warna menjadi elemen yang sangat penting dalam sebuah perancangan baik perancangan sebuah benda maupun sebuah ruangan, sebuh benda atau ruangan yang memiliki warna-warna yang memberikan efek nyaman, sejuk dan segar akan lebih menarik minat seseorang untuk melihat banda tersebut, atau betah berlama-lama dalam sebuah ruangan yang membuat seseorang tersebut merasa yaman dan bahagia.

\section{f. Tekstur}

Tekstur ialah sebuah permukaan yang timbul dari sebuah banda, lantai atau tembok yang dapat dirasakan pada saat disentuh maupun dilihat, sebuah tekstur juga dapat memicu emosional orang yang merasakan entah itu emosi postif atupun emosi negatif tergantung dari sudut pandang orang tersebut. Tekstur memiliki bebrrapa fungsi yakni:

1. Sebagai pemberi kesan visual

2. Peningkatan kualitas ruangan

3. Dunia digital printing.

Tekstur tidak hanya ada dalam dunia desain saja namun juga terdapat setiap bidang seni desain berikut beberapa jenis tekstur dalam seni desai:

1. Tekstur semu

2. Tekstur nyata

3. Tekstur pada makanan

4. Tekstur asli

5. Tekstur gelap terang

6. Tekstur dalam desain grafis

7. Tekstur dalam seni mudik

8. Tekstur tanah

g. Cahaya

Cahaya merupakan elemen paling jelas dari sebuah desain interior. Cahaya yang digunakan bias berupa cahaya alami yang didapat dari sinar matahari maupun sinar rembulan. Atau cahaya buatan seperti lampu. Tanpa adanya cahaya dalam sebuah desain 
maka unsur-unsur yang ada dalam desain interior seperti warna, tekstur, pola dan yang lainnya tidak akan mendapatkan hasil yang maksimal.

h. Pola

Pola ialah sebuah motif atau gambar yang terdapat pasa benda, tembok atau lantai dalam sebuah ruangan yang menambah nilai keindahan dari sebuah desain. Biasanya pola memiliki unsur keberlanjutan atau berulang-ulang hingga memenuhi suatu objek tertentu.

\section{i. Bentuk nyata}

Bentuk nyata ialah bentuk secara umum, bentuk nyata dapat dihasilkan memalui penggabungan dua jenis bentuk umum atau menggabungkan dua jenis elemen seperti elemen pola dan warna yang akan menghasilkan sebuah bentuk yang memiliki warna dan pola tertentu. Bentuk nyata terbagi menjadi dua jenis yaitu;

1. Bentuk buatan manusia (Geometris)

2. Bentuk alam (Organic)

\section{III.3. Data Visual}

Data visual dibutuhkan untuk melihat langsung kondisi lokasi yang akan dijadikan sebagai media pengaplikasian, beberapa langkah pengumpulan data secara visualisasi;

a. Dokumentasi

Dokumentasi dibutuhkan sebgai perbandingan pada saat Lorong kampus sebelum menjadi medaia pengaplikasian dari perancangan glowing in the dark Lorong kampus universitas potensi utama tepatnya data diambil di Gedung B universitas potensi utama.

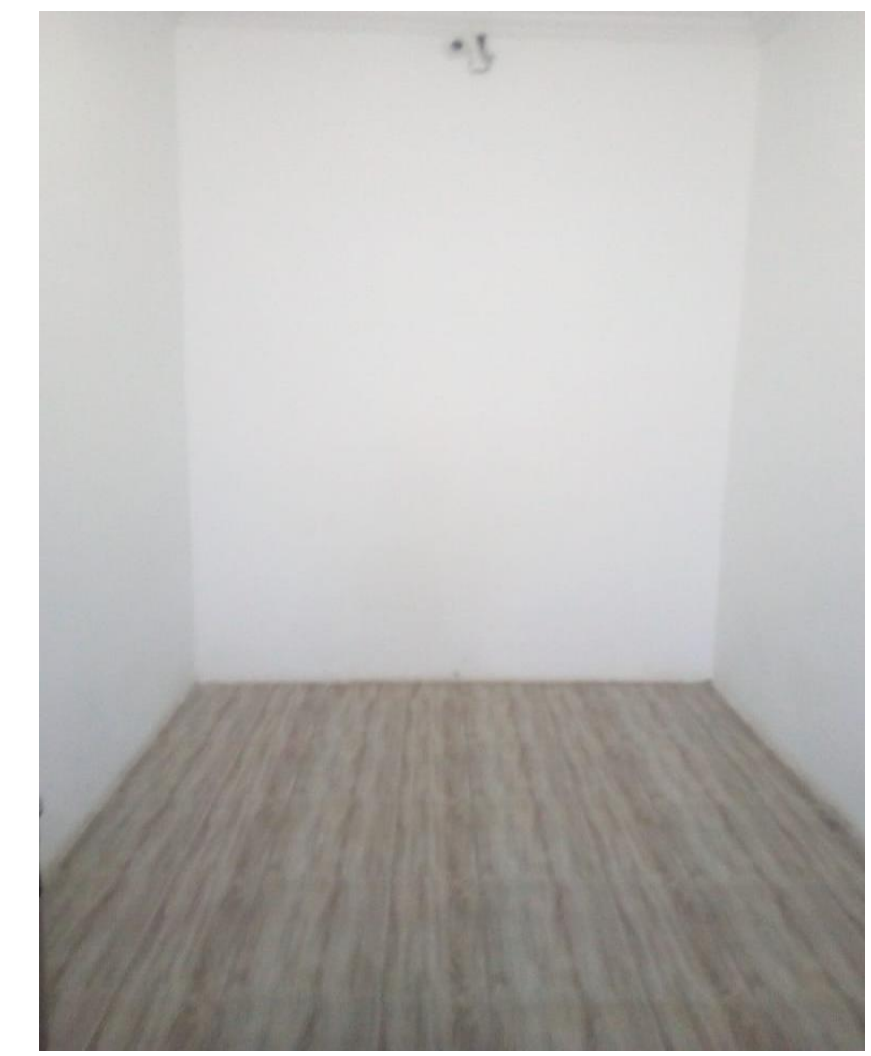

Gambar 1. Lorong yang akan dijadikan tempak pengaplikasian "Glowing In The Dark" 
III.4. Identifikasi Data dan Analisis Data

a. Identifikasi Data

- Lorong kampus belum tersentu dengan sebuah karya seni yang menunjukan bahwah universitas potensi utama memiliki fakultas seni dan desain.

- Untuk menunjukan exsistensi dari program studi desain interior maka dibutuhkan sebuah karya nyata yang menggambarkan program studi desain interior.

b. Analisis Data

Analisis masalah;

- What: apa yang akan dibuat? perancangan glowing in the dark pada Lorong kampus universitas potensi utama sebagai bentuk perwujutan dari program studi desain interior.

- Where: dimana akan diaplikasikan atau diterapkan? Perancangan glowing in the dark pada Lorong kampus universitas potensi utama akan di aplikasikan pada Gedung B universitas potensi utama.

- When: Siapa target sasaran? Target sasaran dari perancangan glowing in the dark ialah seluruh mahasiswa dan sifitas universitas potensi utama.

- Who: kapan dilakukan? Proses Perancangan golowing in the dark dimulai dari bulan September sampai dengan selesai.

- Why: mengapa diciptakan? Gloeing in the dark dirancang untuk memberikan sentuhan seni pada lingkungan kampus universitas potensi utama.

- How: bagaimana merancang? Glowing in the dark dirancang dengan cara menetapkan lokasi yang akan dijadikan sebagai media pengaplikasian dan pemilihan bahan cat yang akan digunakan harus sesuai dengan lingkungan kampus.

III.5. Hasil Karya utama.

Hasil dari perncangan glowing in the dark pada Lorong kampus universitas potensi

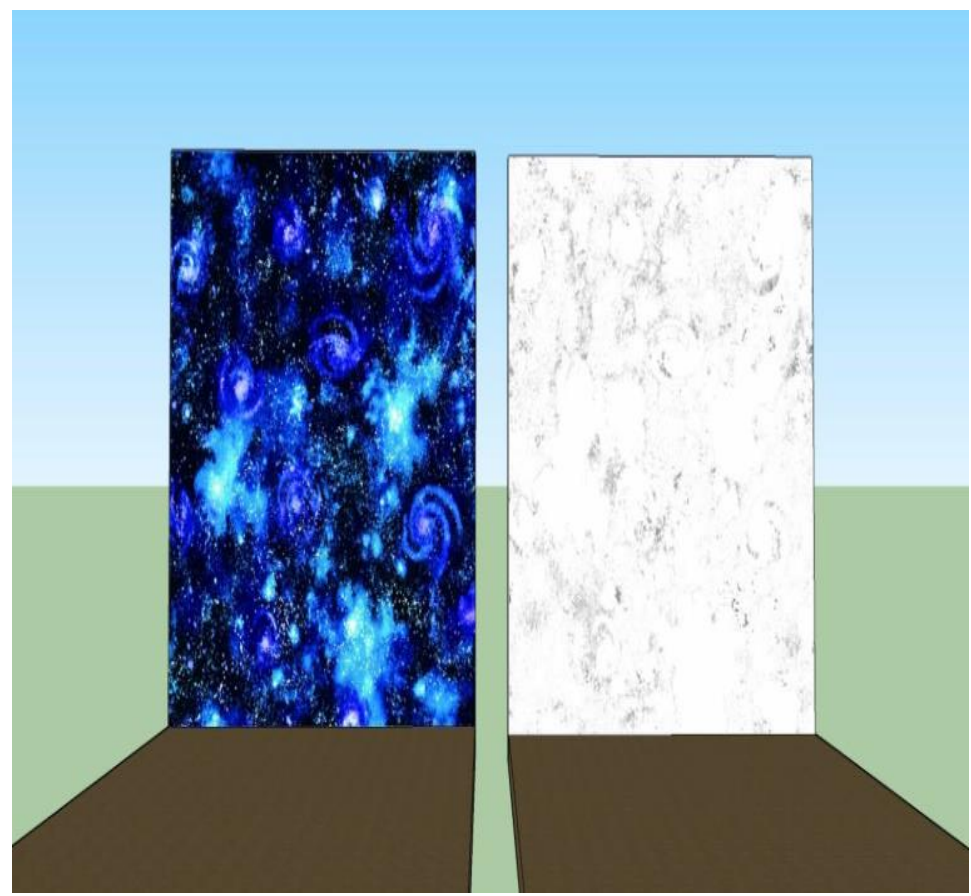

Gambar 2: Desain awal Glowing in the dark 


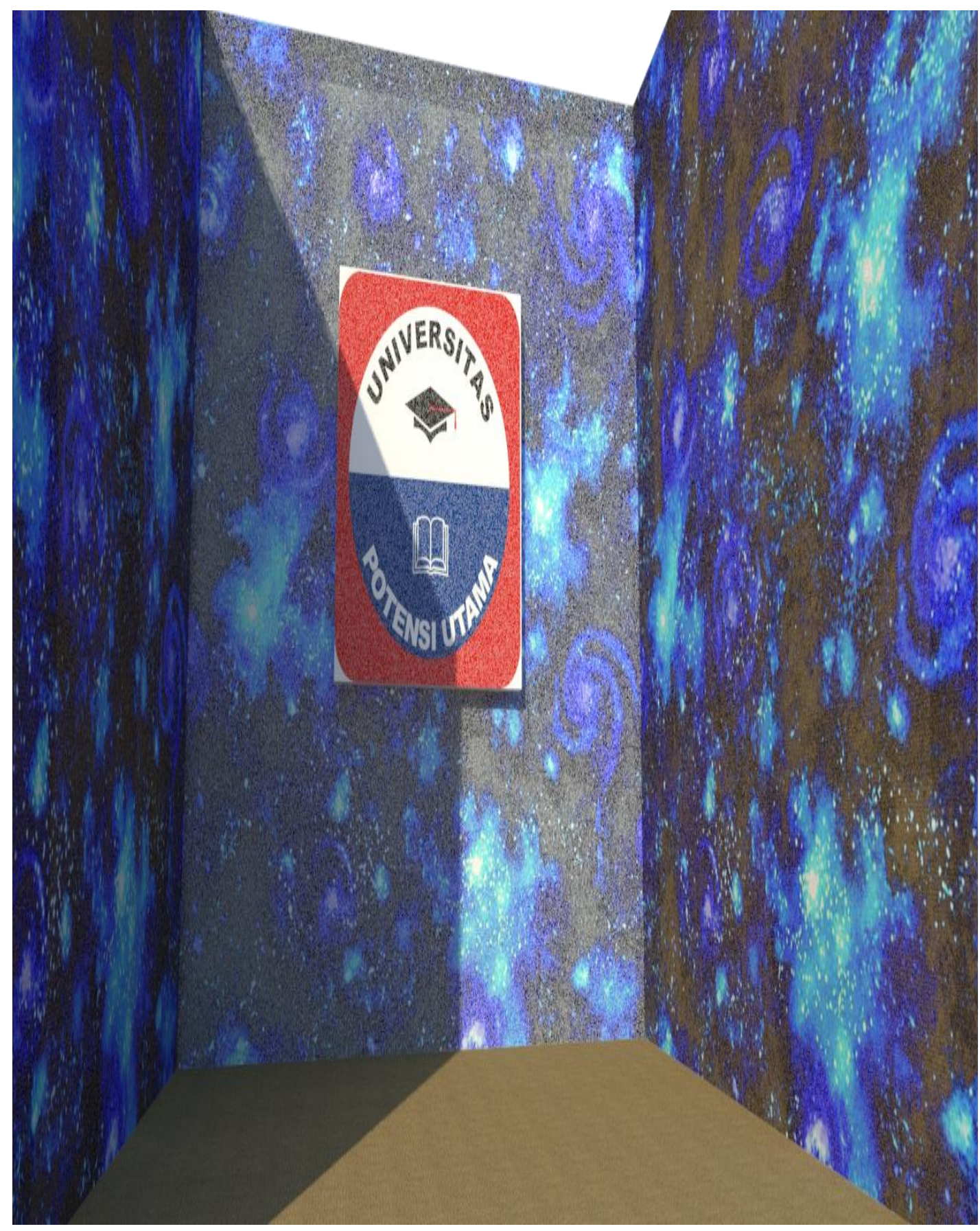

Gambar 3. Glowing in the dark pada saat Light off 


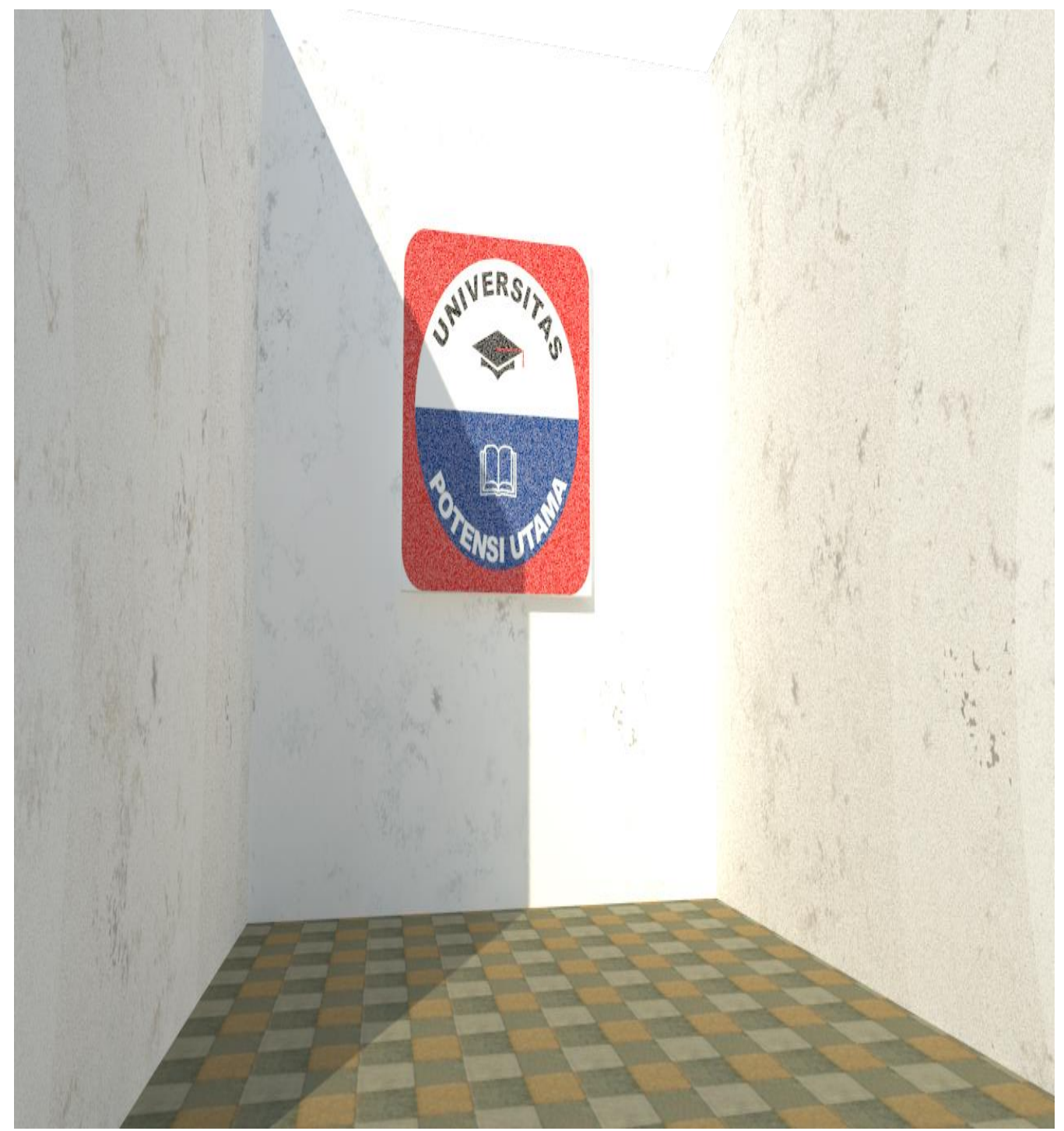

Gambar 4. Glowing in the dark pada saat Light on

\section{KESIMPULAN}

Universitas potensi utama ialah sebuah universitas yang awalnya hanya memiliki fakultas yakni fakultas Teknik informatika namun dengan usaha dan perjuangan dari ketua Yayasan universitas dan seluruh staff yang ada dalam universitas potensi utama maka universitas potensi utama berkembang dengan baik dan diberikan kesempatan untuk membuka beberapa fakultas baru dan dalah satu dari fakultas yang dibuka ialah fakultas seni dan desain yang memiliki tiga program studi yakni program studi desain komunikasi visual, desain interior dan televisi film.

Karena masih barunya fakultas seni dan desain universitas potensi utama oleh sebab itu belum terlihatnya fakultas seni dan desai di lingkungan kampus universitas potensi utama. Perancangan glowing in the dark pada Lorong kampus universtas potensi utama dirancang untuk membangkitkan nilai seni desai pada lingkungan universitas serta menunjukan exsistensi dari program studi desai interior yang menjadi salah satu program studi yang ada pada fakultas seni dan desain universita potensi utama. 
Glowing in the dark ialah sebuah penamaan untuk jenis cat yang dapat berbinar atau bercahaya bila keadaan gelap hal ini dikarnakan cara kerja dari cat glowing in the dark meyerap cahaya yang ada disekitarnya dan membiaskannya kembali saat keadaan disekitarnya gelap.

Lorong kampus adalah tempat yang pada umumnya hanya dilewati begitu saja tanpa ada hal yang dapat mengalikan fokus orang-orang yang melewati Lorong tersebut.dengan perancangan ini diharapkan Lorong yang bila dalam keadaan gelap dapat memancarkan cahaya yang akan mengalikan fukus dari orang-orang yang lewat di Lorong tersebut.

\section{DAFTAR PUSTAKA}

[1] Akbar taufiq. 2014. Wayang Kulit Glowing In The Dark. Jurnal Desain. Vol. 02. No. 02, 61-116

[2] Dewi ni made emmi nutrisia. 2015. Perancangan Maket Sebagai Media Visual Ide Rancangan Suatu Karya Desain Interioe. Jurnal Desain Interior Vol. 2 No 1, 7-13

[3] Rachmayanti Sri. 2014. Green Design Dalam Desain Interior Dan Arsitektur. Jurnal Humaniora Vol. 5

[4] Rahayu Ni Nyoman Sri. 2015. Menata Ruang Sempit Agar Terlihat Lebih Luas. Jurnal Desain Interior Vol. 2. No. 1, 1-6

[5] Saktinah rahma. 2014. Pendekatan Tema Jelajahi Dalam Konsep Dan Rancangan Perpustakaan Sebagai Ruang Publik. Jurnal Sains dan Semi Pomits Vol. 3 